\title{
Current Trends in Percutaneous Nephrolithotomy in China: A Spot Survey
}

\author{
Yuguang Jiang' \\ Jiqing Zhang' \\ Ning Kang' \\ Yinong Niu' \\ Zhiwen $\mathrm{Li}^{2}$ \\ Changlian $\mathrm{Yu}^{3}$ \\ Junhui Zhang'
}

'Department of Urology, Beijing ChaoYang Hospital, Capital Medical University, Beijing, 100020, The People's Republic of China; ${ }^{2}$ Institute of Reproductive and Child Health, Peking University, School of Public Health, Peking University, Beijing, I00I9I, The People's Republic of China; ${ }^{3}$ Department of Urology, The First Affiliated Hospital of Baotou Medical College, Inner Mongolia University of Science and Technology, Baotou, 0I40I0, The People's Republic of China
Correspondence: Junhui Zhang Department of Urology, Beijing ChaoYang Hospital, Capital Medical University, 8 Gongren Tiyuchang Nanlu, Chaoyang District, Beijing, 100020, The People's Republic of China

Tel +86 I0 8523 I 242

Fax +86 1085231082

Email zhang42368dcg@I63.com

Changlian Yu

Department of Urology, The First Affiliated Hospital of Baotou Medical College, Inner Mongolia University of Science and Technology, 4I Linyin Road, Kundulun District, Baotou, 014010, The People's Republic of China

$\mathrm{Tel}+86-472-2178378$

Fax +86-472-2I 29235

Email yuch_lian@163.com
Objective: To describe trends in the procedure of percutaneous nephrolithotomy (PCNL) in China to identify training needs

Methods: A spot survey with 36 questions, which revealed demographic data, patterns of PCNL practice, and opinions regarding specific clinical cases, was administered to Chinese urologists during the $17^{\text {th }}$ National Urological Urolithiasis Symposium held in Dandong in 2018. Results: Out of 400 participants, 221 responses to the survey were received. PCNL was performed by $80.5 \%$ of the participants, and $70.2 \%$ of them were senior clinicians. It was found that $91 \%$ used the prone decubitus in training programs and $27.6 \%$ the modified supine, and $46.6 \%$ were apprenticeship trained for PCNL, while 5.6\% trained during their residency. The prone position was the preferred decubitus, even for obese patients. All of the urologists established their own access, $93.7 \%$ used ultrasonography guidance alone, $70.7 \%$ used ultrasonic and/or pneumatic lithotripters, and $29.2 \%$ used laser. When exiting the kidney, $73.8 \%$ placed a nephrostomy tube whereas $26.2 \%$ used the tubeless technique. For postoperative follow-up, $51.3 \%$ used computed tomography (CT) or ultrasonography plus kidney-ureter-bladder (KUB) to monitor the results of procedures, while $45 \%$ used KUB alone. Colonic injury was reported by $8.9 \%$. Average hospital stays of $>3$ days were reported for $81.2 \%$ of procedures.

Conclusion: Chinese urologists obtain their own access during PCNL, with ultrasonic guidance in most cases, and almost a half of them are apprenticeship trained. They prefer the prone position, use fascial dilators, and place a nephrostomy tube when exiting the kidney. Most urologists follow the official management guidelines in special cases. Skilled use of urological ultrasound examination, flexible nephroscopy, postoperative CT, tubeless procedures in selected patients, and urology residency training are recommended for PCNL practice.

Keywords: survey, calculi, percutaneous nephrolithotomy, PCNL, trends

\section{Introduction}

Percutaneous nephrolithotomy (PCNL) has a well-defined role in the treatment of large and complex renal stones. ${ }^{1-3}$ Despite significant advances in ureteroscopic efficacy, ${ }^{4,5}$ recent studies have demonstrated an increase in the rates of PCNL use, in particular in those countries that are more reliant on reusable instrumentation. ${ }^{6}$ However, of the complete armamentarium of renal stone treatment, PCNL has been considered the most complicated technique to teach.

The incidence of kidney stones has increased over the past three decades. ${ }^{7}$ In China, the growing prevalence of stone disease has reached $6.5 \%$ in women and $5.1 \%$ in men, ${ }^{8}$ which highlights the importance of a better understanding of current regional 
practices. ${ }^{9}$ A few studies in the literature report trends in PCNL among endourologists in different countries, ${ }^{10,11}$ but no data is yet available for China.

This survey aimed to characterize the contemporary practice patterns of PCNL in China and to explore different aspects of the technique and the guidelines for kidney stone management, thus providing an opportunity for the description of regional treatment strategies and specific recommendations for training programs.

\section{Materials and Methods}

An institutional review board-approved questionnaire on trends in PCNL was given to participants at the 17th National Urological Urolithiasis Symposium held in Dandong, China, in November 2018. Consisting of 36 questions (see Figure 1), this anonymous survey collected demographic data in the first seven questions, while the eighth question was for the urologist not performing PCNL. The remaining 28 questions were related to practice setting, postgraduate education, number of cases performed annually and details pertaining to steps and techniques of PCNL practice, as well as opinions regarding specific clinical case scenarios.

Uncomplicated cases were defined as non-staghorn stones in a patient without neurogenic bladder or urinary diversion. Obesity was defined as having a body mass index (BMI) above $26 \mathrm{~kg} / \mathrm{m}^{2}$. Complex cases were defined as those with staghorn calculi, abnormal anatomy, or urinary diversion. The urologists were categorized based on their years of practice and PCNL caseload in the previous year. PCNL technical details were evaluated and compared between the groups.

The statistical analysis was conducted using IBM SPSS Statistics 23.0 (IBM Knowledge Center, USA). The procedural details of PCNL were evaluated and comparisons made between each group using Chi-Square tests and Fisher exact tests. A Student's $t$-test was used to compare continuous data. The statistical tests were two-sided, with $\mathrm{P}<0.05$ taken to indicate statistical significance.

\section{Results}

\section{PCNL Non-Practitioner Group Characteristics}

Of 400 symposium participants, 221 responded to the survey, 178 of whom (80.5\%) performed PCNL regularly and 43 of whom (19.5\%) never carried out PCNL. Table 1 presents the

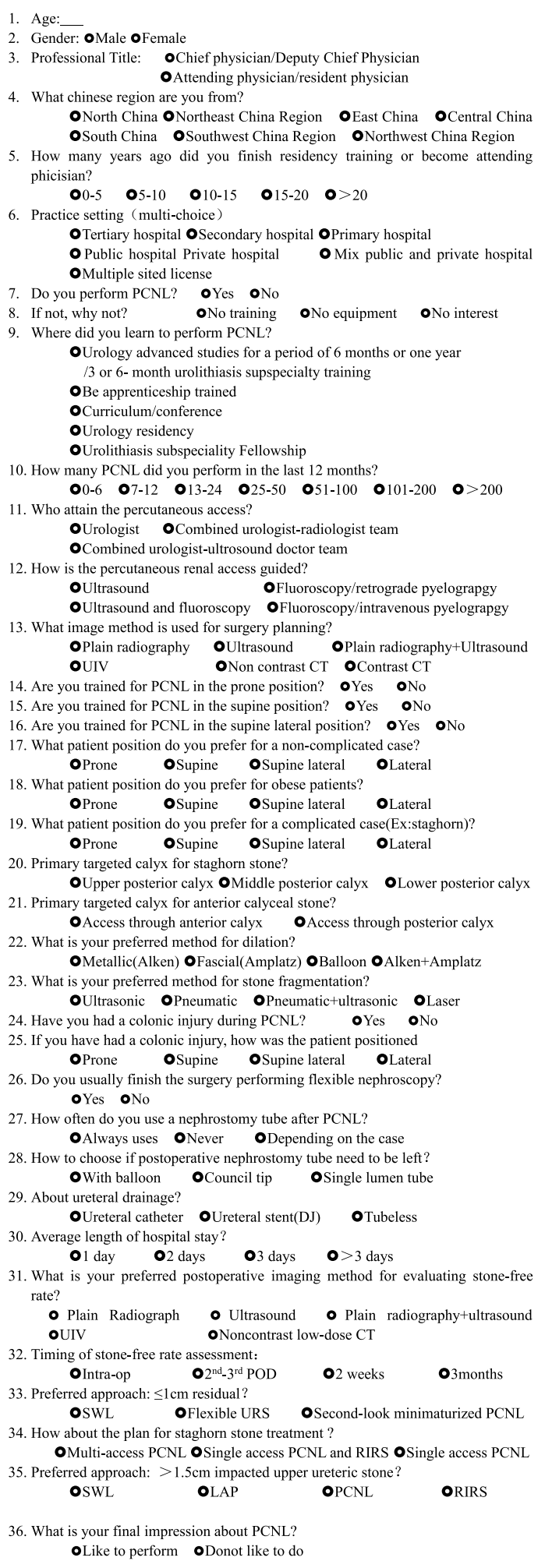

Figure I Questionnaire about current PCNL trends in China. Percutaneous nephrolithotomy (PCNL) is the first-line treatment for complicated renal stones. This survey is aimed to describe trends in the procedure of percutaneous nephrolithotomy (PCNL) in China to identify training needs. The questions I 7 are for all urologists and the eighth question for the urologist not performing PCNL, while the remaining 28 questions are for urologists performing PCNL procedure. 
Table I Demographics of All Respondents (Performers and Non-Performers)

\begin{tabular}{|c|c|c|c|c|c|}
\hline \multirow[b]{2}{*}{ Characteristic } & \multirow[b]{2}{*}{ Group } & \multirow{2}{*}{$\begin{array}{c}\text { All Responders } \\
\text { (n) }\end{array}$} & \multicolumn{2}{|c|}{ Perform PCNL } & \multirow[b]{2}{*}{$P$-value } \\
\hline & & & Yes & No & \\
\hline Gender(n) & $\begin{array}{l}\text { Female } \\
\text { Male }\end{array}$ & $\begin{array}{c}4 \\
217\end{array}$ & $\begin{array}{c}1.7 \%(3) \\
98.3 \%(175)\end{array}$ & $\begin{array}{c}2.3 \%(\mathrm{I}) \\
97.7 \%(42)\end{array}$ & 0.582 \\
\hline $\begin{array}{l}\text { Years since being } \\
\text { attending physician }\end{array}$ & $\begin{array}{l}0-5 \\
5-10 \\
10-15 \\
15-20 \\
>20\end{array}$ & $\begin{array}{l}51 \\
65 \\
36 \\
17 \\
52\end{array}$ & $\begin{array}{l}18.0 \%(32) \\
28.7 \%(51) \\
18.0 \%(32) \\
7.9 \%(14) \\
27.5 \%(49)\end{array}$ & $\begin{array}{c}44.2 \%(19) \\
32.6 \%(14) \\
9.3 \%(4) \\
7.0 \%(3) \\
7.0 \%(3)\end{array}$ & $\begin{array}{l}0.001 \\
0.006\end{array}$ \\
\hline Practice setting & $\begin{array}{l}\text { Primary Hospital } \\
\text { Secondary } \\
\text { Hospital } \\
\text { Tertiary Hospital }\end{array}$ & $\begin{array}{c}1 \\
26 \\
194\end{array}$ & $\begin{array}{c}0.0 \%(0) \\
11.8 \%(2 I) \\
88.2 \%(I 57)\end{array}$ & $\begin{array}{c}2.3 \%(1) \\
11.6 \%(5) \\
86.0 \%(37)\end{array}$ & 0.242 \\
\hline Region & $\begin{array}{l}\text { North } \\
\text { Northeast } \\
\text { East } \\
\text { Central } \\
\text { South } \\
\text { Southwest } \\
\text { Northwest }\end{array}$ & $\begin{array}{l}44 \\
36 \\
62 \\
22 \\
21 \\
23 \\
13\end{array}$ & $\begin{array}{l}19.1 \%(34) \\
13.5 \%(24) \\
28.1 \%(50) \\
11.2 \%(20) \\
11.2 \%(20) \\
10.7 \%(19) \\
6.2 \%(11)\end{array}$ & $\begin{array}{c}23.2 \%(10) \\
27.9 \%(12) \\
27.9 \%(12) \\
4.7 \%(2) \\
2.4 \%(1) \\
9.3 \%(4) \\
4.7 \%(2)\end{array}$ & 0.267 \\
\hline Age in years $(n)$ & $\begin{array}{l}<30 \\
3 I-40 \\
4 I-50 \\
5 I-60\end{array}$ & $\begin{array}{l}13 \\
83 \\
74 \\
20\end{array}$ & $\begin{array}{c}2.6 \%(4) \\
41.7 \%(63) \\
43.0 \%(65) \\
12.6 \%(19)\end{array}$ & $\begin{array}{c}23.1 \%(9) \\
51.3 \%(20) \\
23.1 \%(9) \\
2.6 \%(1)\end{array}$ & 0.000 \\
\hline Age & Mean(SD) & & $41.7(7.2)$ & $37.3(7.5)$ & 0.001 \\
\hline Training & $\begin{array}{l}\text { Urology } \\
\text { residency }\end{array}$ & & $5.6 \%(10)$ & unknown & \\
\hline
\end{tabular}

demographics of the two groups. There were significant differences between them with respect to the amount of time they had been an attending physician $(p=0.001)$, but a greater proportion of the PCNL non-practitioners had been in practice for less than 10 years $(76.8 \%$ vs $46.8 \%$; $p=0.001)$, while a smaller proportion of them had been in practice for more than 20 years $(7.0 \%$ vs $27.5 \%$; $\mathrm{p}=0.006)$, and a smaller proportion of them held senior positions $(10.1 \%$ vs $89.9 \%$; $\mathrm{p}=0.00$ ). Generally, PCNL non-practitioners were younger than PCNL practitioners ( 37.3 vs 41.7 years; $\mathrm{p}=0.001$ ). The differences between the groups in gender, practice setting, or the seven parts of China they were from were not statistically significant. Lack of training (66\%), lack of interest (37\%), or non-availability of equipment $(7 \%)$ were the reasons why PCNL non-practitioners did not incorporate PCNL into their practice.

\section{PCNL Practitioner Group Characteristics}

Amongst the 178 PCNL practitioners, the male gender was predominant (93.3\%), 81.9\% had been an attending physician for more than 5 years, and $70.2 \%$ now had senior positions while $24.7 \%$ were still attending physicians. In terms of training, $46.6 \%$ were apprenticeship trained, $30.8 \%$ learned to perform PCNL during six months to one year of urology advanced study or three to six months of urolithiasis subspeciality training, $14.6 \%$ trained at a curriculum/conference, but only $5.6 \%$ during a urology residency, and none of them during a fellowship. With regard to type of hospital, $88.2 \%$ worked in tertiary hospitals while $11.8 \%$ worked in secondary hospitals, and as far as geographical location was concerned, $28.1 \%$ were from East China, 19.1\% from the North, $11.2 \%$ from the South, and $6.2 \%$ from the Northwest. As to their PCNL caseload 
over the last year, $33.3 \%$ of the urologists performed $<25$ PCNL, 24.1\% between 25 and 50, 21.3\% performed between 51 and 100, and another $21.3 \%$ performed $>100$ PCNL.

\section{Technical Aspects}

As shown in Table 2, the majority (73\%) of PCNL practitioners used computed tomography (CT) before PCNL,

Table 2 Differences in Operative Procedures and Surgeon Preferences

\begin{tabular}{|c|c|c|c|}
\hline $\begin{array}{l}\text { Imaging studies preop } \\
\text { Decubitus training }\end{array}$ & $\begin{array}{l}\text { CT } \\
\text { Prone } \\
\text { Supine } \\
\text { Lateral }\end{array}$ & $\begin{array}{c}\mathbf{N} \\
130 \\
160 \\
16 \\
50\end{array}$ & $\begin{array}{c}\% \\
73.0 \% \\
91 \% \\
9.1 \% \\
28.4 \%\end{array}$ \\
\hline $\begin{array}{l}\text { Decubitus preference } \\
\text { Usual case } \\
\text { Complex calculi } \\
\text { Obesity }\end{array}$ & $\begin{array}{l}\text { Prone/Supine/lateral/Modified supine } \\
\text { Prone/Supine/lateral/Modified supine } \\
\text { Prone/Supine/lateral/Modified supine }\end{array}$ & $\begin{array}{l}145 / 2 / 6 / 22 \\
140 / 1 / 4 / 28 \\
116 / 7 / 9 / 39\end{array}$ & $\begin{array}{l}82.9 / 1.1 / 3.4 / 12.6 \\
80.9 / 0.6 / 2.3 / 16.2 \\
67.8 / 4.1 / 5.3 / 22.5\end{array}$ \\
\hline $\begin{array}{l}\text { Renal access } \\
\text { Performed by } \\
\text { Access guidance Imaging } \\
\text { Dilatation Method }\end{array}$ & $\begin{array}{l}\text { Urologist } \\
\text { Ultrasound/Fluoroscopy/US+Fluoroscopy } \\
\text { Amplatz/Amplatz+Alken/Balloon/Alken }\end{array}$ & $\begin{array}{c}178 \\
167 / 3 / 8 \\
115 / 4|/| 5 / 7\end{array}$ & $\begin{array}{c}100 \% \\
93.7 / 1.7 / 4.5 \\
64.6 / 23.0 / 8.4 / 3.9\end{array}$ \\
\hline Plan for anterior calyceal stone & $\begin{array}{l}\text { Access through anterior calyx } \\
\text { Access through posterior calyx }\end{array}$ & $\begin{array}{l}29 / 139 \\
110\end{array}$ & $\begin{array}{l}20.9 \\
79.1\end{array}$ \\
\hline Primary targeted calyx in staghorn & Upper/Middle/lower & $\begin{array}{c}30 / 127 / 2 \\
(159)\end{array}$ & $18.9 / 79.9 / 1.3$ \\
\hline Main Lithotripters used & $\begin{array}{l}\text { Ultrassonic+Pneumatic } \\
\text { Laser } \\
\text { Pneumatic } \\
\text { Ultrasssonic }\end{array}$ & $\begin{array}{l}76 \\
52 \\
25 \\
25\end{array}$ & $\begin{array}{l}42.7 \\
29.2 \\
14.0 \\
14.0\end{array}$ \\
\hline $\begin{array}{l}\text { Kidney drainage without complication } \\
\text { Type of nephrostomy }\end{array}$ & $\begin{array}{l}\text { Nephrostomy tube/Tubeless } \\
\text { Foley catheter } \\
\text { Single lumen tube } \\
\text { Concill catheter }\end{array}$ & $\begin{array}{l}118 / 42(160) \\
80 / 158 \\
77 \\
1\end{array}$ & $\begin{array}{c}73.8 \% / 26.2 \% \\
50.6 \\
48.7 \\
0.6\end{array}$ \\
\hline Ureteral drainage & Ureteral stent $(\mathrm{DJ}) /$ Ureteral catheter & $123 / 37(160)$ & $76.9 / 23.1$ \\
\hline Flexible nephroscope & At the end of surgery & 24 & 13.5 \\
\hline Primary modality of stone-free rate & $\begin{array}{l}\text { CT scan } \\
\text { Plain radiograph } \\
\text { Ultrasound } \\
\text { Plain radiograph+US }\end{array}$ & $\begin{array}{c}50 \\
23 \\
5 \\
32\end{array}$ & $\begin{array}{c}31.3 \\
45 \\
3.1 \\
20.0\end{array}$ \\
\hline Timing of stone-free rate assessment & $\begin{array}{l}\text { Intro-op/2nd-3rd POD/2 weeks } \\
2-3 \text { months }\end{array}$ & $\begin{array}{c}6 / 72 / 45(157) \\
34\end{array}$ & $\begin{array}{c}3.8 / 46.9 / 28.7 \\
21.7\end{array}$ \\
\hline $\begin{array}{l}\text { Average hospital stay } \\
\text { Staghorn treatment plan }\end{array}$ & $\begin{array}{l}\text { I day } / 2 \text { days } / 3 \text { days } />3 \text { days } \\
\text { Multi-access } P C N L \\
\text { Single access } P C N L \text { and flexible URS } \\
\text { Single access } P C N L\end{array}$ & $\begin{array}{c}0 / 4 / 26 / 130(160) \\
103 / 155 \\
38 \\
14\end{array}$ & $\begin{array}{c}0 / 2.5 / 16.3 / 81.2 \\
66.5 \\
24.5 \\
9.0\end{array}$ \\
\hline Impacted upper ureteric $>1.5 \mathrm{~cm}$ & PCNL/URL/LAP/SWL & $76 / 50 / 28 / 3(157)$ & $\begin{array}{c}48.4 / 31.9 / 17.8 / 1.9 \\
(100 \%)\end{array}$ \\
\hline Management of $\leqq I \mathrm{~cm}$ residual stone & SWL/Flexible URS/Second-look PCNL & $89 / 52 / 15(156)$ & $57.1 / 33.3 / 9.6$ \\
\hline
\end{tabular}


including $52.2 \%$ who preferred non-contrast computed tomography (NCCT).

Regarding decubitus training, 160 of 176 respondents $(91.0 \%)$ were trained in the prone position, $50(28.4 \%)$ in the lateral, and $16(9.1 \%)$ in the supine position. Uncomplicated cases, complex calculi, and obese patients were operated on in the prone position by $145 / 175(82.9 \%)$, $140 / 173(80.9 \%)$ and $116 / 171(67.9 \%)$ of PCNL practitioners, respectively. Differences in decubitus preference were observed for obese patients, and a modified supine position was used by $22.5 \%$ of respondents, which was a higher number than the $12.5 \%$ using it for uncomplicated cases $(\mathrm{p}=0.013)$.

Comparing decubitus preference for uncomplicated cases, we found that prone position was preferred above all others by urologists, no matter how many years it was after their becoming an attending physician, while the modified supine was preferred by surgeons $<5$ and 11-20 years after becoming an attending physician $(n=14 / 75,18.7 \%$; $\mathrm{n}=6 / 93,6.5 \%)(\mathrm{P}=0.015)$. No difference in the mean age was observed in the modified supine group (41.4 years $\pm 6.55)$ versus the prone group (41.9 years \pm 7.29$)(\mathrm{p}=0.25)$.

Renal access was established by the PCNL practitioners themselves, $167(93.7 \%)$ of whom used ultrasonic guidance, while three $(4.5 \%)$ preferred combined ultrasonography/fluoroscopy and eight (1.7\%) used fluoroscopy on its own. As regards dilation, 115 (64.6\%) used Amplatz fascial dilators, 41 (23.0\%) preferred sequential Amplatz plus Alken metal telescoping dilators, while a balloon was favored by 15 (8.4\%) and Alken by $7(3.9 \%)$. When asked about the main lithotripters they preferred to use, $76(42.7 \%)$ of the respondents preferred combined ultrasonic and ballistic devices and 52 used (29.2\%) laser, while $25(14.0 \%)$ chose the ultrasonic and another $25(14.0 \%)$ the ballistic lithotripter. At the end of the procedure, 24 (13.5\%) of the respondents used a flexible nephroscope for residual stones not detected by ultrasonography or fluoroscopy. From questions 27-32 we obtained 160 responses. At the end of a PCNL without complications, 118 (73.8\%) left a nephrostomy tube, while $42(26.2 \%)$ used a tubeless technique. A ureteral stent was also left by 123 (76.9\%), while $37(23.1 \%)$ preferred a ureteral catheter.

Fifty $(31.3 \%)$ of 160 respondents assessed the stonefree rate by CT, $32(20.0 \%)$ by ultrasonography plus kidney-ureter-bladder (KUB), 23 (45\%) by KUB, and 5 $(3.1 \%)$ by ultrasonography. Meanwhile, there was also no consensus on the most appropriate timing for a stone-free rate assessment, and $21.7 \%$ did so at three months, $28.7 \%$ after two weeks, and $46.9 \%$ after 48 hours. In our survey, $130(81.2 \%), 26(16.3 \%)$, and $4(2.5 \%)$ of 160 respondents reported their patients had an average hospital stay of $>3$ days, 3 days, and 2 days, respectively.

\section{The Management Modalities Chosen in Special Cases}

For staghorn stones, 103 (66.5\%) of 155 respondents used PCNL monotherapy with multiple access, while PCNL monotherapy with single access was adopted by only 14 urologists (9\%). More notably, 38 (24.5\%) combined flexible ureteroscopy with PCNL for complex staghorn stones. Overall, 123 (79.4\%) used middle posterior calyx access as the primary targeted calyx.

For impacted upper ureteric stones of $>1.5 \mathrm{~cm}, 48.4 \%$ of 157 responders used PCNL, 31.9\% used URL, and $17.8 \%$ laparoscopic lithotomy.

Regarding the management of $\leq 1 \mathrm{~cm}$ residual stones, $57.1 \%$ of 156 respondents used Shockwave Lithotripsy (SWL), 33.3\% used flexible ureteroscopy, and 9.6\% second-look miniaturized PCNL.

\section{Colonic Injury}

Data on colonic injury during PCNL was collected. From 178 PCNL practitioners, we received 157 responses, with $14(8.9 \%)$ reporting colonic injury at least once during their practice. Thirteen of these fourteen responded to a question about patient positioning when there was a colonic injury, and $10(76.9 \%)$ reported this complication in the prone position, and $3(23.1 \%)$ in the modified supine $(\mathrm{P}=0.007)$. Colonic injury and PCNL cases in the previous year were relative, and colonic injury occurred in $9(26.5 \%)$ with $>100$ cases, $3(8.1 \%)$ with 51-100 cases, and 2 (5.1\%) with 25-50 PCNL cases last year $(\mathrm{P}=0.01)$. Thirteen of the 14 respondents reporting a complication had senior professional titles, and colonic injury occurred in $6(46.2 \%)$ of them in practice for more than 20 years, $4(30.8 \%)$ of them in practice for 10-19 years, and $3(23.1 \%)$ of them in practice for less than 10 years after becoming an attending physician $(\mathrm{P}=0.446)$.

\section{Urologists' Opinion About PCNL}

When talking about their opinion of the procedure, the majority $(96.2 \%)$ of 156 respondents liked performing it, 
which showed its popularity despite the difficulties regarding technique and potential complications.

\section{Discussion}

According to the management guidelines of the European Association of Urology (EAU) and the American Urological Association (AUA), PCNL is the first-line treatment for stones larger than $2 \mathrm{~cm}$, complex kidney stones, $>1.5 \mathrm{~cm}$ inferior calyx stones, symptomatic calyceal and diverticular lithiasis, lithiasis failed SWL and retrograde intrarenal surgery (RIRS) $)^{3,12}$

The prevalence of stone disease is increasing dramatically worldwide, ${ }^{13}$ and the number of PCNLs accounts for about $5-10 \%$ of all the treatment for urinary stones in the departments of urology. However, PCNL utilization has widely varied, whether in developed countries or in developing areas, due to its availability and access, the economic implications of its use, and the differences in health systems between countries, as well as the different levels of training, which underlies the importance of gaining a better understanding of current local and global practices. ${ }^{5,11,14-16}$

Through this questionnaire survey, we studied PCNL trends in a select population of Chinese participants in a urolithiasis symposium. It is the first research into PCNL practice patterns in China. Respondents were from all over the country, but mainly from economically developed East China, and the fewest were from the relatively undeveloped Northwest regions. To some extent, the spread of the population of the urologists across the regions reflects the geographical economic differences, the universality of calculi and the extent of the attention being paid to this issue.

Comparing PCNL practitioners with PCNL nonpractitioners, we observed different levels of experience, with a smaller proportion of PCNL non-practitioners in practice for more than 20 years after becoming an attending physician and significantly younger than PCNL practitioners. In other words, PCNL is preferentially performed by older urologists who had become senior physicians and developed enough PCNL experience to practice independently. Most new Chinese graduates will work in a team with the role of "physician assistant" and will not have the chance of practicing PCNL independently until they become senior physicians. This, however, may change after the National Specialty Residency Training System mandate. ${ }^{17}$

The analysis of the PCNL non-practitioners showed that their reasons for not performing PCNL included lack of training or interest. While 54\% of PCNL practitioners were apprenticeship trained, a mere 5.6\% received training during a urology residency, which is considered to be the most effective process for developing the skills. ${ }^{18}$ The data from our study suggests that urology residency training programs should be encouraged.

It was observed that more of the PCNL practitioners were from the East and North regions, $88.2 \%$ had practiced in tertiary hospitals and $11.8 \%$ in secondary hospitals. As to PCNL caseloads in the previous year, 33.3\% performed at most 24 PCNLs last year, while $66.7 \%$ performed at least 25 PCNLs. Some studies have estimated a trainee must perform approximately 24 PCNLs to attain proficiency during residency and demonstrated that $>33$ PCNLs per year is enough caseload for the maintenance of skills. ${ }^{18-20}$ Therefore, most urologists had a sufficient volume of cases for developing and maintaining their skills.

The vast majority, $91.0 \%$, of PCNL practitioners were trained to attain percutaneous renal access in the prone position, and only $9.1 \%$ in supine decubitus, which was significantly less than the $64 \%$ reported by Batagello et al. ${ }^{10}$ Regarding patient decubitus, the prone position was preferred for both uncomplex $(82.9 \%)$ and complex cases $(81.0 \%)$. Whether a case of complex kidney stones or otherwise, the prone position has still been the preferred position for a higher stone-free rate and familiarity, but the supine position, especially the modified supine, is gaining more popularity among some of the urologists in our study, which is in line with other studies reporting the advantages of the combined anterograde and retrograde approaches in this position with regard to the management of complex renal stones. ${ }^{14,21,22}$

Obtaining adequate and safe percutaneous access is the hallmark of a good PCNL. Standard methods for obtaining access include fluoroscopic or ultrasound guidance. In this survey, most PCNL practitioners (93.7\%) preferred ultrasound guided renal puncture over combined ultrasound/ fluoroscopy $(4.5 \%)$ or fluoroscopy alone $(1.7 \%)$, in contrast to the CROES data which revealed that $86.3 \%$ of patients had percutaneous punctures and tract dilations with fluoroscopy versus $13.7 \%$ guided by ultrasound guidance. ${ }^{23}$ Ultrasound guidance for PCNL has gained acceptance amongst urologists given its numerous advantages over fluoroscopy. ${ }^{24-27}$

Urologists either performing the access procedures or actively directing radiologists can ensure effective access for a subsequent PCNL. According to Sri and Carlos, $77 \%$ or even more urologists established their own access. ${ }^{10,11}$ 
Our results indicated the renal access was achieved exclusively by a urologist, which can be explained by the availability of the training system for puncture/dilation under ultrasound guidance and the complete up-to-date imaging equipment as well as the avoidance of radiation exposure.

As to the dilation technique, $64.6 \%$ used Amplatz dilation, 21.3\% preferred Amplatz plus reusable Alken metal telescopic dilation while only $8.4 \%$ used a balloon, which was in line with the results of the CROES study that found that there was a preference for progressive dilatation in developing countries, and the most common use of one-step balloon dilatation was in developed counties. ${ }^{28}$ This difference indicates balloon dilation is limited in China due to its higher cost, and training for balloon dilation with ultrasound guidance should be encouraged to obviate repetitive and time-consuming dilation, especially in economically developed regions.

PCNL practitioners preferred combined ultrasonic/pneumatic lithotripters $(41.6 \%)$ or laser $(25 \%)$ over either ultrasonic-only (14\%) or pneumatic-only (14\%), which was different from the results of the CROES data and Batagello's study, which stated that pneumatic-only lithotripters or ultrasoniconly were used more frequently, followed by combination ultrasonic/pneumatic and, finally, laser. ${ }^{29}$ This can be explained by the fact that combination devices fragment complex and large-volume calculi efficiently, and the holmium laser has become the mainstay of lithotripsy for miniaturized PCNL.

With improved endoscopes, better ancillary tools, and growing experience with percutaneous surgery, the need for secondary procedures is declining. In properly selected patients the tubeless technique appears to be safely used. $^{14,22,30}$ In contrast to the results from CROES (8.8\%), the tubeless technique was used by $26.2 \%$ in our survey, similar to Sivalingam (24\%) and Batagello et al (28.4\%). ${ }^{10,11}$ More recently, the idea of "totally tubeless" has been reintroduced for selected patients but to date, a totally tubeless PCNL is still rare despite its appeal. ${ }^{31,32}$ In our study, a ureteral stent was left by $76.9 \%$ and a ureteral catheter by $23.1 \%$.

Intraoperative high-resolution image examination, routine use of flexible nephroscopy at the end of the procedure, and postoperative $\mathrm{CT}$ to assess the need for intervention in the same admission can maximize the stone clearance rate. ${ }^{33}$ In our study, $13.5 \%$ performed flexible nephroscopy at the end of surgery, and KUB was the preferred postoperative imaging method for $45 \%$, followed by CT for $31.3 \%$, KUB+ultrosound for $20 \%$. This was different from Batagello et al, who reported NCCT for $50 \%$, and KUB for $20.3 \%{ }^{10}$ This phenomenon can be explained by regional disparity in knowledge and the economy.

In our survey average hospital stays of $>3$ days were reported by $130(81.2 \%)$ of the PCNL practitioners, which contrasts with Ahmad's study, in which 1-3 day average hospital stays were reported by $95.9 \%$ of PCNL practitioners. $^{34}$

The results concerning treatment options for staghorn stones showed that most urologists follow the main management guidelines of the EAU, and recently updated AUA, and PCNL is the first-line alternative of choice for the treatment of complex kidney stones. ${ }^{2,3}$ Technological advances mean that urologists often have to choose between different modalities of treatment for the same surgical scenario. According to Ahmad et al, the use of retrograde intrarenal surgery (RIRS) in the Galdakao-modified supine Valdivia position has an increasing role in combination with PCNL in the contemporary management of staghorn stones. ${ }^{34,35}$ In this survey, $24.5 \%$ preferred combined flexible ureteroscopy with PCNL (endoscopic combined intrarenal surgery, ECIRS) for complex staghorn stones. This trend is also reflected by $17.8 \%$ laparoscopic lithotomy for an impacted upper ureteric stone of $>1.5 \mathrm{~cm}$.

Even in expert hands, obtaining completely stone-free outcomes can be challenging. ${ }^{36}$ For $\leq 1 \mathrm{~cm}$ residual stone, 9.6\% preferred second-look miniaturized PCNL with tracts ranging from $18 \mathrm{~F}$ (mini-PCNL) to $5 \mathrm{~F}$ (microPCNL) now available. Accordingly, variation in PCNL technique indicates high-level training programs for any form of lithotripsy, and further training should be mandated.

Colonic injury is generally reported in less than $1 \%$ of cases. $^{36}$ In our study, colonic lesion occurred predominantly in the prone position $(\mathrm{p}=0.007)$, for PCNL practitioners with $>100$ PCNL cases in the previous year $(p=0.01)$, and those with senior professional titles, which is different from that reported by $\mathrm{Wu}$ and Batagello. ${ }^{37}$ Finally, our questionnaire revealed that $8.9 \%$ of PCNL practitioners report this complication at least once in their practice while only $3.8 \%$ do not enjoy performing the procedure, significantly fewer than those reported by Batagello et al. ${ }^{9}$ This can be explained by ultrasonography guided renal puncture having a lower possible risk of adjacent organ injury. ${ }^{38}$

Our study is not without limitations. Since this was a survey, we did not establish explanations for all the observed trends. For example, we were unable to discern 
why urologists chose differently, or the rationale for using a specific approach for the procedure. A follow-up study would be useful in answering these and other related questions. Moreover, our response rate was less than $70 \%$. Nevertheless, the information from this study can contribute to developing training programs for PCNL in China.

\section{Conclusions}

Chinese urologists obtain their own access for PCNL with ultrasonic guidance in most cases, and the majority of them are trained by apprenticeship. They prefer the prone position, use fascial dilators, and place a nephrostomy tube when exiting the kidney. The modified supine decubitus is gaining more popularity. Most urologists follow the main management guidelines in special cases. Skilled use of urological ultrasound examination, training in modified supine position, flexible nephroscopy, postoperative CT for stone free rate assessment, tubeless procedures in selected patients, personalized stone management tailored to the local conditions and individuals, and high-level urology residency training/further education should be encouraged for more effective PCNL practice.

\section{Ethics Approval and Consent to Participate}

I confirm that I have read the Editorial Policy pages. This study was conducted with approval from the Ethics Committee of Beijing Chao-Yang Hospital. This study was conducted in accordance with the declaration of Helsinki. Written informed consent was obtained from all participants.

\section{Acknowledgments}

The authors are very grateful to the professionals participating in the survey for their opinions and recorded experiences; as well as Prof Zhangqun Ye for their support and help in the collection of the data.

\section{Funding}

There is no funding to report.

\section{Disclosure}

The authors declare that they have no conflicts of interest for this work.

\section{References}

1. Fernström I, Johansson B. Percutaneous pyelolithotomy. A new extraction technique. Scand J Urol Nephrol. 1976;10:257-259. doi:10.1080/21681805.1976.11882084
2. Pradère B, Doizi S, Proietti S, Brachlow J, Traxer O. Evaluation of guidelines for surgical management of urolithiasis. $J$ Urol. 2018;199:1267-1271. doi:10.1016/j.juro.2017.11.111

3. Türk C, Petřík A, Sarica K, et al. EAU guidelines on interventional treatment for urolithiasis. Eur Urol. 2016;69:475-482. doi:10.1016/j. eururo.2015.07.041

4. Ghani KR, Sammon JD, Bhojani N, et al. Trends in percutaneous nephrolithotomy use and outcomes in the United States. $J$ Urol. 2013;190:558-564. doi:10.1016/j.juro.2013.02.036

5. Marchini GS, Mello MF, Levy R, et al. Contemporary trends of inpatient surgical management of stone disease: national analysis in an economic growth scenario. $J$ Endourol. 2015;29:956-962. doi:10.1089/end.2015.0021

6. Oberlin DT, Flum AS, Bachrach L, Matulewicz RS, Flury SC. Contempory surgical trends in the management of upper tract calculi. J Urol. 2015;193:880-884. doi:10.1016/j.juro.2014.09.006

7. Sorokin I, Mamoulakis C, Miyazawa K, Rodgers A, Talati J, Lotan Y. Epidemiology of stone disease across the world. World $J$ Urol. 2017;35:1301-1320. doi:10.1007/s00345-017-2008-6

8. Zeng G, Mai Z, Xia S, et al. Prevalence of kidney stones in China: an ultrasonography based cross-sectional study. BJU Int. 2017;120:109-116. doi:10.1111/bju.13828

9. Kauer PC, Laguna MP, Alivizators G, On behalf of the members of ESUT, et al. Present practice and treatment strategies in endourological stone management: resultsof a survey of the European Societyof Uro-technology(ESUT). EUR Urol. 48;2005:182-188. doi:10.1016/j. eururo.2005.01.002

10. Batagello CA, Vicentini FC, Marchini GS, et al. Current trends of percutaneous nephrolithotomy in a developing country. Int Braz J Urol. 2018;44 (2):304-313. doi:10.1590/S1677-5538.IBJU.2017.0292

11. Sivalingam S, Cannon ST, Nakada SY. Current practices in percutaneous nephrolithotomy among endourologists. $J$ Endourol. 2014;28:524-527. doi:10.1089/end.2013.0447

12. Assimos DG, Krambeck A, Miller NL, et al. Surgical management of stones: american urological association/endourological society Guideline, Part II. J Urol. 2016;196:1161-1169. doi:10.1016/j. juro.2016.05.091

13. Sorokin I, Mamoulakis C, Miyazawa K, et al. Epidemiology of stone disease across the world. World J Urol. 2017;35:1301-1320. doi:10.1007/s00345-017-2008-6

14. Ghani KR, Andonian S, Bultitude M, et al. Percutaneous nephrolithotomy: update, trends, and future directions. Eur Urol. 2016;70:382-396. doi:10.1016/j.eururo.2016.01.047

15. Thornton SN, Smith AC, Hanley JM, et al. Urologic diseases in America Project. Prevalence of kidney stones in the United States. Eur Urol. 2012;62:160-165. doi:10.1016/j.eururo.2012.03.052

16. Preminger GM, Assimos DG, Lingeman JE, Nakada SY, Pearle MS, Wolf JS Jr; AUA Nephrolithiasis Guideline Panel). Chapter 1: AUA guideline on management of staghorn calculi: diagnosis and treatment recommendations. J Urol. 2005;173:1991-2000.

17. National health and Family Planning Commission. [Guideline of the Pilot Implementation of Standardized Speciality Training System. 2016]. Available from: http://www.nhfpc.gov.cn/qjjys/s3593/201601/ 0ae28a6282a34c4e93cd7bc576a51553.shtml. Accessed January 11, 2016. Chinese.

18. de la Rosette JJ, Laguna MP, Rassweiler JJ, Conort P. Training in Percutenous Nephrolithotomy-A critical review. Eur Urol. 2008;54:994-1001. doi:10.1016/j.eururo.2008.03.052

19. Kadlec AO, Ellimoottil C, Guo R, et al. Contemporary volume-outcome relationships for percutaneous nephrolithotomy: results from the Nationwide Inpatient Sample. $J$ Endourol. 2013;27:1107-1113. doi:10.1089/end.2013.0172

20. Huang WY, Wu SC, Chen YF, et al. Surgeon volume for percutaneous nephrolithotomy is associated with medical costs and length of hospital stay: a nationwide population-based study in Taiwan. J Endourol. 2014;28:915-921. doi:10.1089/end.2014.0003 
21. Vicentini FC, Torricelli FC, Mazzucchi E, et al. Modified complete supine percutaneous nephrolithotomy: solving some problems. J Endourol. 2013;27:845-849. doi:10.1089/end.2012.0725

22. Sivalingam S, Al-Essawi T, Hosking D. Percutenous nephrolithotomy with retrograde nephrostomy access: aforgotten technique revisited. J Urol. 2013;189:1753-1756. doi:10.1016/j.juro.2012.11.169

23. Jagtap J, Mishra S, Bhattu A, Ganpule A, Sabnis R, Desai MR. Which is the preferred modility of renal access for a trainee urologist: ultrasonography or fluoroscopy? Results of a prospective randomized trial. J Endourol. 2014;28:1464-1469. doi:10.1089/end.2014.0229

24. Tzou DT, Metzler IS, Usawachintachit M, Stoller ML, Chi T. Ultrasound-guided access and dilation for percutaneous nephrolithotomy in the supine position: a step-by-step approach. Urology. 2019;133:245-246.

25. Tzou DT, Usawachintachit M, Taguchi K, Chi T. Ultrasound use in urinary stones: adapting old technology for a modern-day disease. J Endourol. 2017;31(S1):S89-S94. doi:10.1089/end.2016.0584

26. Armas-Phan M, Tzou DT, Bayne DB, Wiener SV, Stoller ML, Chi T. Ultrasound guidance can be uesd safely for renal tract dilation during percutaneous nephrolithotomy. J Urol. 2018;199:1267-1271. doi:10.1016/j.juro.2017.11.111

27. Tzeng BC, Wang CJ, Huang SW, et al. Doppler ultrasound guided percutaneous nephrolithotomy: a prospective randomized study. Urology. 2011;78(3):535-539. doi:10.1016/j.urology.2010.12.037

28. Yamaguchi A, Skolarikos A, Buchholz NP, et al. Operating times and bleeding complications in percutaneous nephrolithotomy: a comparison of tract dilation methods in 5,537 patients in the Clinical Research Office of the Endourological Society Percutaneous Nephrolithotomy Global Study. $J$ Endourol. 2011;25:933-939.

29. Chu DI, Lipkin ME, Wang AJ, et al. Lithotrites postoperative fever: does lithotrite type matter? Results from the clinical research office of the endourological nephrolithotomy global study. Urol Int. 2013;91:340-344. doi:10.1159/000351752
30. Agrawal MS, Sharma M, Agarwal K. Tubeless percutaneous nephrolithotomy using antegrade tether: a randomized study. J Endourol. 2014;28:644-648. doi:10.1089/end.2013.0693

31. Xun Y, Wang Q, Hu H, et al. Tubeless versus standard percutaneous nephrolithotomy: an update meta-analysis. BMC Urol. 2017;17:102.

32. Istanbulluoglu MO, Cicek T, Ozturk B, Gonen M, Ozkardes H. Percutaneous nephrolithotomy: nephrostomy or tubeless or totally tubeless? Urology. 2010;75:1043-1046. doi:10.1016/j.urology.2009. 06.104

33. Portis AJ, Laliberte MA, Drake S, Holtz C, Rosenberg MS, Bretzke CA. Intraoperative fragment detection during percuteneous nephrolithotomy: evaluation of high magnification rotational fluoroscopy combined with aggressive nephroscopy. J Urol. 2006;175:162-165. doi:10.1016/S0022-5347(05)00052-2

34. Ahmad AA, Alhunaidi O, Aziz M, et al. Current trends in percutenous nephrolithotomy: an internet-based survey. Ther Adv Urol. 2017;9:219-226. doi:10.1177/1756287217724726

35. Scoffone CM, Cracco CM, Cossu M, Grande S, Poggio M, Scarpa RM. Endoscopic combined intrarenal surgery in Galdakao-modified supine Valdivia position: a new standard for percutaneous nephrolithotomy? Eur Urol. 2008;54:1393-1403. doi:10.1016/j.eururo.2008.07.073

36. Maghsoudi R, Etemadian M, Kashi AH, Mehravaran K. Management of colon perforation during percutaneous nephrolithotomy: 12 years of experience in a referral center. J Endourol. 2017;31:1032-1036. doi:10.1089/end.2017.0379

37. Yuan D, Liu Y, Rao H, et al. Supine versus prone position in percutaneous nephrolithotomy for kidney Calculi: a meta-analysis. $J$ Endourol. 2016;30:754-763.

38. Gamal WM, Hussein M, Aldahshoury M, et al. Solo ultrasonography-guided percutaneous nephrolithotomy for single stone pelvis. J Endourol. 2011;25:593-596.
Risk Management and Healthcare Policy

\section{Publish your work in this journal}

Risk Management and Healthcare Policy is an international, peerreviewed, open access journal focusing on all aspects of public health, policy, and preventative measures to promote good health and improve morbidity and mortality in the population. The journal welcomes submitted papers covering original research, basic science, clinical \& epidemiological studies, reviews and evaluations, guidelines, expert opinion and commentary, case reports and extended reports. The manuscript management system is completely online and includes a very quick and fair peer-review system, which is all easy to use. Visit http://www.dovepress.com/testimonials.php to read real quotes from published authors. 